\title{
Cidadania para pessoas transgênero no Mercosul: um comparativo entre Brasil e Uruguay
}

\author{
Citizenship for trans people in Mercosur: a legal comparative between \\ Brazil and Uruguay
}

\section{Ciudadanía para personas transgénero en el Mercosur: un comparativo entre Brasil y Uruguay}

\author{
Antônio Rodrigues Neto ${ }^{1, a}$ \\ antonio.neeeto@gmail.com | http://orcid.org/0000-0001-8402-7267 \\ Antônio Leonardo Amorim ${ }^{2, b}$ \\ amorimdireito.sete@hotmail.com | http://orcid.org/oooo-0003-1464-0319
}

\footnotetext{
${ }^{1}$ Universidade Federal de Mato Grosso do Sul. Campo Grande, MS, Brasil.

2 Universidade Federal de Jataí. Jataí, GO, Brasil.

a Graduação em Direito pela Universidade Federal de Mato Grosso do Sul.

b Mestrado em Direito pela Universidade Federal de Mato Grosso do Sul.
}

\section{Resumo}

Este artigo tem como escopo estabelecer, a partir de pesquisa bibliográfica e documental, um comparativo legal entre o aporte jurisprudencial brasileiro (Ação Direta de Inconstitucionalidade $\mathrm{n}^{0}$ 4.275-DF, Supremo Tribunal Federal do Brasil, 2018) e o Projeto de Lei no 816/2017 (Ley Integral para Personas Trans), recentemente aprovado pela Câmara dos Deputados do Uruguai, a fim de combater a discriminação e ampliar direitos para transexuais, transgêneros e travestis no Brasil, considerando-se a necessidade de se expandir a cidadania para essas pessoas: tradicionalmente marginalizados. Busca-se discutir sobre as legislações dos dois países selecionados como objeto de pesquisa (integrantes do Mercosul), a fim de verificar se estão promovendo Direitos Humanos à População T. Como resultado, evidencia-se que, ao passo que o Uruguai tem empreendido esforços na positivação de direitos e no reconhecimento do respeito à autodeterminação da identidade de gênero, o Brasil, ainda, tem caminhado timidamente na mesma construção, dependendo - prioritariamente - de jurisprudências e atos administrativos para tanto.

Palavras-chave: Cidadania; Direitos humanos; Mercosul; População T; Brasil; Uruguai. 


\begin{abstract}
The purpose of this article is to establish, based on bibliographical and documentary research, a legal comparison between the Brazilian jurisprudential contribution (Direct Unconstitutionality Action $n^{0}$ 4,275-DF, Supreme Federal Court of Brazil, 2018) and Bill no 816/2017 (Ley Integral para Personas Trans), recently approved by the Chamber of Deputies of Uruguay, in order to combat discrimination and expand rights for transsexuals, transgenders and transvestites in Brazil, considering the need to expand citizenship for these people: traditionally marginalized. The aim is to discuss the legislation of the two countries selected as an object of research (members of Mercosur), in order to verify if they are promoting Human Rights to Population T. As a result, it is evident that, while Uruguay has made efforts in the positivation of rights and in the recognition of respect for the self-determination of gender identity, Brazil has also walked timidly in the same construction, depending - primarily on jurisprudence and administrative acts for that purpose.
\end{abstract}

Keywords: Citizenship; Human rights; Mercosur; Population T; Brasil; Uruguai.

\title{
Resumen
}

Este artículo tiene como objetivo establecer, a partir de investigación bibliográfica y documental, un comparativo legal entre el aporte jurisprudencial brasileño (Acción Directa de Inconstitucionalidad $\mathrm{n}^{\circ}$ 4.275-DF, Supremo Tribunal Federal de Brasil, 2018) y el Proyecto de Ley no 816/2017 (Ley Integral para Personas Trans), recientemente aprobado por la Cámara de Diputados de Uruguay, a fin de combatir la discriminación y ampliar derechos para transexuales, transgéneros y travestis en Brasil, considerando la necesidad de expandir la ciudadanía para esas personas: tradicionalmente marginados. Se busca discutir sobre las legislaciones de los dos países seleccionados como objeto de investigación (integrantes del Mercosur), a fin de verificar si están promoviendo Derechos Humanos a la Población T. Como resultado, se evidencia que, mientras que Uruguay ha emprendido esfuerzos en la positivación de derechos y en el reconocimiento del respeto a la autodeterminación de la identidad de género, Brasil, aún, ha caminado tímidamente en la misma construcción, dependiendo- prioritariamente - de jurisprudencias y actos administrativos para tanto.

Palabras clave: Ciudadanía; Derechos humanos; Mercosur; Población T; Brasil; Uruguai.

INFORMAÇÕES DO ARTIGO

Este texto faz parte do dossiê $\mathbf{4 0}$ anos do movimento LGBT: visibilidades e representações.

Contribuição dos autores:

Concepção e desenho do estudo: Antônio Rodrigues Neto; Antônio Leonardo Amorim.

Aquisição, análise ou interpretação dos dados: Antônio Rodrigues Neto; Antônio Leonardo Amorim.

Redação do manuscrito: Antônio Rodrigues Neto; Antônio Leonardo Amorim.

Revisão crítica do conteúdo intelectual: Antônio Rodrigues Neto; Antônio Leonardo Amorim.

Declaração de conflito de interesses: não há.

Fontes de financiamento: CAPES (Coordenação de Aperfeiçoamento de Pessoal de Nível Superior).

Considerações éticas: não há.

Agradecimentos/Contribuições adicionais: não há.

Histórico do artigo: submetido: 31 jan. 2019 | aceito: 31 maio 2019 | publicado: 12 set. 2019.

Apresentação anterior: não houve.

Licença CC BY-NC atribuição não comercial. Com essa licença é permitido acessar, baixar (download), copiar, imprimir, compartilhar, reutilizar e distribuir os artigos, desde que para uso não comercial e com a citação da fonte, conferindo os devidos créditos de autoria e menção à Reciis. Nesses casos, nenhuma permissão é necessária por parte dos autores ou dos editores. 


\section{Introdução}

A difusão de debates sobre as questões de gênero e diversidade sexual em diferentes espaços públicos e privados, nacional e internacionalmente, tem possibilitado uma maior compreensão sobre o tema, ressignificando compreensões, esclarecendo preconceitos e, sobretudo, permitindo o acesso a um robusto conjunto de informações sobre sexualidade, sexo biológico e gênero, capazes de sedimentar o respeito à igualdade pela diferença e a construção da cidadania para pessoas cuja identidade (sexual, de gênero, ou ambas) seja dissidente.

Em razão da importância que as questões de gênero e diversidade sexual têm no que se refere ao pleno desenvolvimento da pessoa e seu preparo para a cidadania, bem como no enfrentamento à ameaças e lesões a Direitos Humanos, à proteção de mulheres, homossexuais, bissexuais, intersexuais, transgêneros, transexuais e travestis deve ser uma das garantias do Estado Social de Direitos, pois são agentes políticos e sociais para quem se evidenciam limitações/ausência de alguma liberdade e/ou direitos: o que se convencionou chamar por minorias.

Por isso, com frequência, surgem perante a comunidade internacional - global e regional - novos documentos que visam proteger liberdades e direitos em razão de gênero e diversidade sexual, dentre os quais - em apertada síntese - é possível citar: Declaração Universal dos Direitos Humanos, adotada e proclamada pela Assembleia Geral das Nações Unidas, em 10 de dezembro 1948'; Convenção Americana de Direitos Humanos, também conhecida como Pacto de San José da Costa Rica, de 22 de novembro de 1969²; Convenção Interamericana para Prevenir, Punir e Erradicar a Violência Contra a Mulher - Convenção de Belém do Pará, de 9 de junho de 1994³ entre outros.

Todavia, no que se refere à População $\mathrm{T}^{\mathrm{i}}$, muitos ainda são os entraves para que essas pessoas gozem de uma proteção isenta de estigmas e discriminações e, mais que isso, para que sejam resguardados direitos e liberdades sem quaisquer distinções; resultando na sua inserção social tradicionalmente marginalizadas e na promoção estatal do reconhecimento de direitos, de visibilidade e de uma verdadeira transformação social sobre as múltiplas formas como as pessoas podem se relacionar afetiva e sexualmente ou como manifestar o gênero (ou nenhum gênero) que entende como mais adequado para si.

Dito isso, o presente trabalho é de caráter descritivo, bibliográfico e documental, que objetiva, a partir de metodologias comparativas, comparar a jurisprudência brasileira (Ação Direta de Inconstitucionalidade (ADI) $\mathrm{n}^{0}$ 4.275-DF, Supremo Tribunal Federal - STF/2018) e o uruguaio Projeto de Lei no 816/2017 (Ley Integral para Personas Trans - LIPT), recentemente aprovado pela Câmara dos Deputados do Uruguai, no combate à discriminação e no reconhecimento/ampliação direitos para transexuais, transgêneros e travestis ${ }^{5,6}$.

Dessa realidade é que surge o problema da presente pesquisa: de que forma a ADI no 4.275/DF/STF/2018 e a LIPT se aproximam (ou afastam) da construção da cidadania para pessoas transgêneros no Mercosul?

Dessa forma, o presente artigo está dividido em duas partes. Inicialmente, se ocupa de conceituar a População $\mathrm{T}$ e sua relação com o direito à igualdade pela diferença e cidadania. Posteriormente, estão qualitativamente analisadas e comparadas as disposições da ADI $n^{0}$ 4.275/DF/STF/2018 e da LIPT, estabelecendo-se a importância do reconhecimento legal de direitos a essas pessoas para a garantia de sua participação social, econômica, educacional, cultural e política.

Ao final, chega-se à conclusão pela necessidade de garantias de promoção e proteção da dignidade da pessoa humana e dos direitos humanos da População T. Além disso, o comparativo estabelecido entre Brasil e Uruguai, demonstrou que, mesmo que em ritmos e formas diferentes, ambos os países analisados

\footnotetext{
i Para melhor desenvolvimento e compreensão do texto, doravante será utilizada a expressão 'População T' para se fazer referência aos grupos de pessoas transexuais, travestis e transgêneros, malgradas as diferentes significações sociais e políticas para os termos 'transexual', 'transgênero' e 'travesti't. Para fins deste artigo, considerar-se-á todas essas identidades como espectros de uma mesma expressão que visa a ruptura com a norma de gênero compulsória.
} 
apresentaram certa preocupação com a proteção e inserção social de transgêneros. A ausência de lei específica no Brasil, todavia, torna frágeis jurisprudências e políticas públicas conquistadas.

\section{População T: do respeito à igualdade pela diferença à conquista da cidadania}

Nos últimos anos, a transexualidade vem ganhando mais evidência para o ramo do direito e, consequentemente, maior projeção nas academias (faculdade), afastando-se, cada vez mais, das dicotomias binárias existentes e voltando-se à necessidade de enfrentamento e regulamentação da proteção e promoção de Direitos Humanos para a população T7 .

Com isso, pode-se extrair que quando se trata de questões onde se discute gênero ou orientação sexual, necessariamente estar-se-á diante de situações que devem ser discutidos em conjunto questões que envolvem direitos humanos, dignidade da pessoa humana, haja vista são valores que vão muito além de questões regionalizadas, bem como envolvem todo um país ou bloco de países, como o nosso caso em estudo ${ }^{8}$.

As questões de gênero necessariamente envolvem a dignidade do ser humano, pois o gênero é a raiz da pessoa humana e, eventual ocorrência de discriminação viola direito de a pessoa ser quem se é, ou seja, promoção de sua dignidade.

A medicina por muito tempo considerou sexo como formação particular que seria modo ensejador a distinguir os sexos como sendo macho e fêmea, nos mesmos moldes que dos animais e vegetais, no entanto, essa classificação ao ser interpretada para os seres humanos causa estigma e forma preconceitos ${ }^{9}$, no entanto, essa mesma medicina tem avançado em seus estudos sobre a temática, assim, o conceito de macho e fêmea passou a se tornar bastante incerto ${ }^{10}$.

Assim, a transexualidade pode ser tanto masculina quanto feminina, que se verifica a título de exemplo com o homem que se sente como mulher e a mulher que se sente como homem. Consigna que se objetiva nesse trabalho não discutir todas as questões de genro e as conceituando, mas sim, a defesa pela cidadania de todos gêneros, de um modo peculiar dos transgêneros.

A conceituação dos termos 'transgêneros', 'travestis' e 'transexuais' (a 'População T', para fins do presente artigo), por sua vez, esbarra na própria essência dessas manifestações de gênero, que é a de fugir da existência de uma padronização naturalizada. Ressalta-se que qualquer definição aqui trazida pode, inevitavelmente, não contemplar todas as identidades dissidentes, considerando a existência do princípio da autodeterminação e, ainda, que é dinâmico o processo de surgimento de novas manifestações de gênero e diversidade sexual.

A Opinión Consultiva $\mathrm{n}^{0}$ 24, de 24 de novembro de 2017, da Corte Interamericana de Direitos Humanos, que trata do direito de pessoas transgênero mudarem seu prenome e sexo jurídico independentemente de cirurgia de transgenitalização e quaisquer laudos de profissionais da saúde, define por "h) Transgênero ou pessoa trans: Quando a identidade ou a expressão de gênero de uma pessoa é diferente daquela que tipicamente se encontra associada com o sexo designado no nascimento. As pessoas trans constroem sua identidade independentemente de um tratamento médico ou intervenções cirúrgicas. O termo 'trans' é um termo guarda-chuva utilizado para descrever as diferentes variantes da identidade de gênero, cujo denominador comum é a não-conformidade entre o sexo designado ao nascer da pessoa e a identidade de gênero que tem sido tradicionalmente associada a ele. Uma pessoa transgênero ou trans pode identificar-se com os conceitos de homem, mulher, homem trans, mulher trans e pessoa não binária, bem como com outros termos como hïjra, terceiro gênero, biespiritual, travesti, fa'afadine, queer, transpinoy, muxé, waria e meti. A identidade de gênero é um conceito diferente da orientação sexual”"

E, ainda, denomina “i) Pessoa transexual: As pessoas transexuais se sentem e se concebem a si mesmas como pertencentes ao gênero oposto que social e culturalmente se associa a seu sexo biológico e optam por uma intervenção médica - hormonal, cirúrgica ou ambas - para adequar sua aparência físico-biológica à sua realidade psíquica, espiritual e social. j) Pessoa travesti: Em termos gerais, se poderia dizer que as pessoas travestis são aquelas que manifestam 
uma expressão de gênero - seja de maneira permanente ou transitória - mediante a utilização de roupas ou atitudes do gênero oposto que social e culturalmente são associadas ao sexo designado no nascimento. Pode incluir ou não a modificação do seu corpo" ${ }^{11}$.

Aprofundada a compreensão sobre a População T, passa-se a abordar a relação entre cidadania, enquanto direito a ter direitos, respeito à igualdade pela diferença e pessoas transgênero ${ }^{12,13}$.

A cidadania por sua vez, ainda não se mantém como símbolo de igualdade para todos, visto que ao longo da história surgem classes privilegiadas, quando então, os trabalhadores, as mulheres e os mais pobres são excluídos, por isso, historicamente sempre precisaram se afirmar, o que ocorre com as lutas por melhoria de vida para suas respectivas classes $^{14}$. Percebe-se que da própria essência do que é ser cidadão, dependerá do grau e de posição que essa pessoa ocupa na sociedade. É considerado cidadão toda pessoa que tem reconhecimento social, ou seja, aquela que se apresenta com características humanas, no entanto, sabe-se que as características do conceito de cidadania assumem dimensão característica de cada época ou situação ${ }^{14}$. Isso não significa que aquele não tenha esses estereótipos não seja considerado ser humano, no entanto, nem sempre será considerado cidadão.

Assim, vale ressaltar que por não haver distinção entre os seres humanos na Constituição Federal de 1988 (art. $5^{\text {oii }}$ ), qualquer denominação de gênero, merece proteção por melhores condições de garantias da dignidade da pessoa humana e do reconhecimento como cidadão, o que decorre do direito fundamental à igualdade.

O direito fundamental à igualdade tem estrita correlação com o Estado Democrático de direito, com a filosofia jurídica e com a teoria geral do direito, como fonte formadora para a concretização do bem comum ${ }^{15}$.

A igualdade tratada como princípio fundamentador da ordem jurídica constitucional é considerada como meio suficiente de promoção da dignidade da pessoa humana e dos direitos humanos, pode ser compreendida como todas as normas escrita ou não, que resguardam direitos fundamentais em normas do tipo regra. Para que a norma seja suficiente para resguardar a efetividade da igualdade, deve necessariamente ser uma norma plural, que permita a sua combinação com várias outras regras, norma genérica, que são suficientes para que normas fundamentais de direitos humanos possam quando de sua aplicabilidade compreender o maior número de pessoas possíveis, por isso, quando da evolução e chamamento de normas de direitos humanos, superando a antiga nomenclatura "direito do homem", foi suficiente a proteger o maior número de pessoas possível ${ }^{15}$.

A igualdade como princípio se apresenta em sua dimensão formal, a busca incansável pela superação da desigualdade existente entre as pessoas, assim, para esse princípio as normas existentes em um país devem ser universalizadas, para que todos superem as desigualdades existentes e, sejam tratados de forma igual ${ }^{15}$. Desse modo, a igualdade como princípio fundante da promoção da dignidade da pessoa humana, o qual objetiva superar as desigualdades existentes.

Desse modo, a igualdade tem como sua configuração a eficácia transcendente, ou seja, as desigualdades que persistirem até a entrada em vigor de uma norma constitucional, não devem ser recepcionadas, tendo em vista a progressão em direitos e garantias da dignidade da pessoa humana proclamadas na nova ordem constitucional ${ }^{17}$.

Sendo que qualquer forma de violação aos valores contidos na Constituição Federal de 1988, seja ele por meio de uma norma, como também de situações de desigualdades que venham a minar a eficácia do princípio da igualdade não se mostra compatível com os valores do texto constitucional ${ }^{17}$.

De outro lado, o termo igualdade sem a ocorrência de desigualdade não se tem muito sentido, nessa perspectiva os iguais devem ser tratados com igualdade, por conseguinte, o desigual, deve ter o reconhecimento

ii "Art. $5^{\circ}$ Todos são iguais perante a lei, sem distinção de qualquer natureza, garantindo-se aos brasileiros e aos estrangeiros residentes no País a inviolabilidade do direito: à vida, à liberdade, à igualdade, à segurança e a à propriedade, nos seguintes termos ${ }^{\prime 15}$. 
de sua desigualdade para fins de tratamento. Por isso, ao fazer essa lógica interpretativa, chegar-se-á ao que entende Aristóteles sobre o que é tratamento igual aos desiguais ${ }^{18 .}$

Em complemento a esse entendimento, entende-se que existe o direito de ser igual quando a diferença inferioriza toda pessoa, já que todos têm o direito de ser diferente quando a sua igualdade o descaracteriza, o que justifica então, a necessidade plena e efetiva da existência de uma igualdade que, reconheça todas as diferenças, além de não criar nenhuma diferença que produza ou reproduza qualquer espécie de desigualdade ${ }^{13}$.

Muito embora, seja inerente ao ser humano o reconhecimento da igualdade no Estado Democrático de Direito, deve, esse reconhecimento de igualdade ser interpretado em conformidade com as desigualdades existentes para determinadas pessoas.

O gênero tem como construção diversas formas de diferenças de classes, raça, etnia, não apenas o sexo, por isso, a experiência de um ser humano em ser mulher, negro ou transgênero nunca será singular, mas sim, uma experiência de múltiplas situações, principalmente em um país em que as questões de gênero não têm recebido o tratamento adequado de ensino, para que em um futuro a igualdade deixe de ser uma utopia ${ }^{19}$.

O reconhecimento da igualdade não é fim da promoção do reconhecimento de melhores condições de vida para a população T, pois como mencionado o Brasil ainda carece de normas legais que promovam essa igualdade.

Considera-se que como fundamento último da perspectiva dos direitos humanos é a defesa da dignidade da pessoa humana, visto que, a partir da promoção da dignidade da pessoa humana é que se garantirá a efetividade dos direitos humanos, em toda sua completude ${ }^{19}$.

A dignidade da pessoa humana apenas se concretizará quando for considerada base e eixo principal de um Estado, que dará base ao universo de direitos e garantias individuais, bem como dando integral cumprimento ao que o constituinte originário de 1988 chamou de princípio basilar do Estado Democrático de Direito, o que se apresenta como garantidor da promoção da dignidade humana assegurada constitucionalmente ${ }^{20}$.

Por fim, relacionando a dignidade humana e a necessidade de atuação estatal para a universalização do acesso a direitos, ressalta-se que "[...] a cidadania tem como pressuposto a existência de direitos para que as pessoas possam ter uma vida autônoma. Essa autonomia depende de condições objetivas e subjetivas de participação da vida social. Se as primeiras estão relacionadas com acesso a condições materiais, as segundas requerem o reconhecimento da igual dignidade dos indivíduos. Os direitos fundamentais são manifestações dessas condições necessárias para a realização da liberdade pessoal. Eles implicam a universalidade do acesso, o que nos permite dizer que são os direitos públicos subjetivos. Entretanto, eles também possuem uma dimensão objetiva, que enfatiza o papel das instituições estatais na realização desses direitos. Temos então diante de nós uma estrutura normativa centrada no dever governamental de promover a justiça social, um princípio que obviamente ocupa um papel extremamente importante na efetivação da cidadania", pontos esses que também se destacam na ADI no 4.275/DF/STF/2018 e na LIPT 4,5,21.

Nesse sentido, o Brasil necessita de implementar mais garantias e direitos para a população $\mathrm{T}$, como forma de garantia da cidadania para essas pessoas e, por conseguinte, da efetivação dos direitos humanos que decorrerá da afirmação e do reconhecimento das questões de gênero.

\section{ADI $n^{\circ} 4.275 / D F / S T F / 2018$ e a ley integral para personas trans: um comparativo legal em sede do Mercosul}

Conforme anteriormente apontado, a construção da cidadania para a População T, (enquanto 'direito a ter direitos', perpassa diferentes espaços públicos e privados e, principalmente, enseja na consagração da igualdade enquanto promoção do bem de todos, sem discriminação, a partir da transformação social voltada à superação de estigmas, exclusão e violências sociais e estatais, que caracterizam a situação dessas pessoas, com o especial fim de garantir-lhes a dignidade, em uma perspectiva de Direitos Humanos ${ }^{6,12,16}$. 
Dessa forma, voltando-se o recorte da pesquisa para o âmbito do Mercosul, o presente estudo ocupar-se de analisar, comparativamente, os aparatos legais brasileiro e uruguaio, no que se refere à construção/ reconhecimento de direitos para a População T.

Sobre a metodologia comparativa, "Consiste em investigar coisas ou fatos e explicá-los segundo suas semelhanças ou diferenças. Geralmente, o método comparativo aborda duas séries ou fatos de natureza análoga, tomados de meios sociais ou de outra área do saber, a fim de detectar o que é comum a ambos"².

Para tanto, a sistematização do método para a análise dos conteúdos jurídicos, estabelece como etapas "[...] 1) a escolha dos objetos de comparação; 2) a apresentação das características e funções jurídicas de cada objeto nos respectivos ordenamentos jurídicos; 3) a contextualização de cada objeto sob a perspectiva macro jurídica e, quando possível e necessário, sob a perspectiva extrajurídica; 4) a comparação em sentido estrito; 5) o exame das diferenças e pontos comuns encontrados ao longo da comparação e 6) a elaboração de críticas aos objetos estudados e de eventuais propostas de aperfeiçoamento dos sistemas em que eles se inserem com base nas conclusões comparativas [...]"23.

A partir da metodologia comparativa, passa-se à análise dos objetos. No Brasil, em se tratando da legislação produzida a fim de tutelar-se direitos da População T, "As leis dos diversos países que dispõem sobre direitos das pessoas trans mudam de acordo com a compreensão que o legislador tenha do que seja gênero. Quanto mais próximo de uma visão biologizante de gênero maiores serão as exigências para as cirurgias de transgenitalização e as mudanças nos documentos "[...] 'O que se observa no Brasil é a total ausência de uma legislação que assegure os direitos fundamentais às pessoas trans'. Atualmente, há três projetos de lei que tramitam no Congresso Nacional: o PL 72/2007, do ex-deputado Luciano Zica; o PLS 658/2011, da ex-senadora Marta Suplicy; e o PL 5002/2013, do deputado Jean Wylys e da deputada Érika Kokai”’24.

A inexistência de legislação específica voltada à proteção da População T no Brasil contrasta com realidades diferentes em outros países. Prosseguindo, "A crescente mobilização pelo reconhecimento pleno de ativistas trans (transexuais, travestis, intersexos, transgêneros e queer) em diversos países tem possibilitado conquistas, a exemplo das leis de identidade de gênero espanhola, argentina, 'uruguaia' e inglesa. De forma geral, essas legislações normatizam as cirurgias de transgenitalização e a mudança nos documentos para as pessoas trans. Entre as legislações há diferenças consideráveis. No Brasil, no entanto, há uma criatividade inédita no cenário internacional: inventou-se o nome social para as pessoas trans. São normas que regulam o respeito à identidade de gênero em esferas micro: nas repartições públicas, em algumas universidades, em bancos”24.

A política pública a que se refere os textos acima, denominada nome social, possibilitou a transgêneros, sem alteração do registro civil, compatibilizar seus nomes (neste caso, o nome pelo qual eram conhecidos dentre seus pares) e a sua identidade psíquica e social de gênero, acrescentando-o aos seus documentos de identificação. O Decreto $\mathrm{n}^{0}$ 8.727, de 28 de abril de 2016, portanto, regulou o uso do nome social e o reconhecimento da identidade de gênero de pessoas travestis e transexuais no âmbito da administração pública federal direta, autárquica e fundacional ${ }^{25}$.

Outro ponto de destaque é previsão da realização de cirurgias de redesignação sexual e do fornecimento do tratamento hormonal pelo Sistema Único de Saúde, direito introduzido pela Portaria no 457, de 19 de agosto de 2008, e ampliado pela Portaria ${ }^{0}$ 2.803, de 2013, ambas do Ministério da Saúde ${ }^{26,27}$.

Por outro lado, a ADI n ${ }^{0}$ 4.275/DF/STF/2018 pode ser considerada o principal expoente jurisprudencial em favor da População T no país, ao reconhecer a importância da autodeterminação de gênero como principal parâmetro para a conquista de direitos a essas pessoas e possibilitar a transgêneros a alteração de registro civil sem a necessidade de realização de procedimento cirúrgico para redesignação de sexo mediante averbação no registro original, independentemente de cirurgia de transgenitalização e sem a necessidade, ainda, de procedimento de jurisdição voluntária (em que não há litigio) ou de autorização judicial para tanto5.

Há que se mencionar, todavia, que os requisitos para implementação do direito foram estabelecidos por meio do Provimento n. 73, de 28 de junho de 2018, do Conselho Nacional de Justiça, que traz em seu 
artigo $4^{\circ}, \S 6^{\circ}$, um total de 17 documentos requeridos para a averbação da alteração do prenome e do gênero nos assentos de nascimento e casamento de pessoa transgênero no Registro Civil das Pessoas Naturais5 ${ }^{5,28}$.

Ou seja, até a votação da $\mathrm{ADI} \mathrm{n}^{0}$ 4.275/DF/STF/2018, as principais conquistas versavam sobre a possibilidade de uso do nome social como meio de efetivação de sua dignidade (Decreto $\mathrm{n}^{0}$ 8.727/2016) e de realização do procedimento de transgenitalização pelo Sistema Único de Saúde (Portaria ${ }^{0}$ 2.803/2013/Ministério da Saúde), mas que ainda precisa conviver com estigmas patologizantes; marginalização educacional e laboral e, principalmente, dados alarmantes de violência transfóbica ${ }^{5,25,27,29}$.

Com isso, o que se extrai do panorama brasileiro de proteção à População $\mathrm{T}$ é que a inexistência de leis próprias culmina em insegurança jurídica a essas pessoas, uma vez que a conquista de direitos e liberdades, aqui associados à cidadania, acaba se dando unicamente por meio de políticas públicas ou do ativismo judicial, que podem ser revogadas de acordo com novos interesses governamentais e/ou entendimentos jurídicos.

Já acerca da legislação do Uruguai voltada à proteção, reconhecimento e promoção da identidade transgênero, verifica-se que o país foi o primeiro da sua região a adotar uma lei de identidade de gênero e promoção das pessoas transexuais, a Lei $\mathrm{n}^{0} 18.620$, de 17 de novembro de 2009, bem como estabeleceu especificamente $\mathrm{o}$ conceito jurídico de crimes de ódio baseados na "orientação sexual" e "identidade sexual", nos termos da Lei no 17.677, 29 de julho de 2003, pelos quais "[...] os crimes de ódio consistem em agravante de pena de prisão - de entre $6 \mathrm{e}$ 24 meses - à sanção imposta pelo crime cometido [...]" e desenvolveu a Lei no 17.817, de 6 de setembro de 2004, que declarou como interesse nacional, dentre outras, a luta contra todas as formas de discriminaçãa ${ }^{30}$.

Nesse contexto, o Projeto de Lei $\mathrm{n}^{0}$ 816/2017, aprovado pelo Congresso uruguaio em outubro de 2018 e, ainda, pendente de sanção presidencial, institui a LIPT, que define os conceitos de "identidade de gênero", "manifestação de gênero", "homem/mulher trans"; garante a visibilidade trans, inserindo nos censos oficiais a opção 'identidade de gênero'; facilitando a mudança de nome das pessoas trans no registro civil, instituindo a Comissão de Mudança de Identidade e Gênero, que será responsável pelos trâmites de adequação registral, de caráter sigiloso, e elaboração de novo registro, possibilitando, inclusive, o retorno para o prenome e sexo originais após cinco anos da mudança; desenvolvimento de ações afirmativas para inclusão laboral, educacional e de acesso à moradia; reparação indenizatórias por parte do Estado e, por fim, a proibição de qualquer tipo de discriminação ou patologização no acesso ao sistema público de saúde ${ }^{6}$.

De acordo com o aludido Projeto de Lei, a criação de uma lei específica à População T surge da "[...] necesidad de impulsionar una serie de acciones que aborden la situación de las personas trans desde un enfoque integral que abarque distintas dimensiones de la vida: salud, educación, trabajo, vivienda, cultura. Es fundamental tener en cuenta las relaciones mutuas y necesarias entre los distintos derechos y el reconocimiento de que la garantía de unos será dependiente o contribuirá al disfrute de otros, al igual que la vulneración de unos incidirá en la afectación de otros"6.

Por sua vez, vincula-se à construção da cidadania uma vez que "[...] busca considerar la complejidad de la situación de exclusión y discriminación que enfrenta la población trans. De ahí que se establece una serie de acciones que tienen por objetivo revertir los mecanismos de discriminación y estigmatización y garantir a las personas trans el pleno ejercicio de sus derechos de ciudadanía. [...] De este modo se contribuirá a garantizar el pleno ejercicio en condiciones de igualdad de sus derechos y libertades, promoviendo el respeto a su dignidad, buscando lograr la integración social a nivel cultural, económico-laboral, en el ámbito de la salud y la educación, así como en cualquier otro ámbito de la vida ciudadana”.

Dito isso, valendo-se da metodologia comparativa, ao passo que evidencia-se um robusto conjunto de leis voltadas à proteção dos interesses da População T no território uruguaio, com amplas previsões que abrangem inúmeros aspectos da vivência social dessas pessoas e o incentivo à transformação social necessária à sua inclusão (igualdade), os quais virão a ser exponencialmente alargados com a aprovação do uruguaio Projeto de Lei $n^{\circ}$ 816/2017 pelo chefe do executivo, no Brasil as maiores conquistas com o mesmo propósito restringem-se a jurisprudências e atos administrativos, o que demonstra lentidão nos processos de criação de políticas e leis direcionadas à garantia da cidadania, enquanto direitos a ter direitos à População $\mathrm{T}^{6,12}$. 


\section{Considerações finais}

A decisão da ADI n⿳0 4.275/DF/STF/2018, ao expandir a noção jurídica de identidade de gênero e de transgênero e permitir a interpretação do artigo 58, da Lei no 6.015, de 31 de dezembro de 1973, conforme a Constituição Federal de 1988, reconhece direitos dessas pessoas tradicionalmente marginalizados e promove a igualdade pela diferença, emergindo como principal expoente jurisprudencial em favor da População T no Brasil, que até então estava restrita à utilização do nome social e realização de processo transgenitalizador pelo Sistema Único de Saúde. Todavia, embora a referida decisão represente relevantes avanços em sede de garantia de Direitos Fundamentais e Direitos Humanos, o Provimento ${ }^{0}$ 73/2018, do Conselho Nacional de Justiça, pode vir a limitar o acesso ao direito conquistado, em razão da complexidade do procedimento estabelecido ${ }^{5,16,28,31}$.

Por outro lado, em se tratando do Uruguai, o país foi o primeiro da sua região a adotar uma lei de identidade de gênero e promoção das pessoas transexuais, a Lei $n^{0} 18.620 / 2009$, bem como estabeleceu especificamente o conceito jurídico de crimes de ódio baseados na "orientação sexual" e "identidade sexual", nos termos da Lei $n^{0} 17.677 / 2003$, desenvolveu a Lei $n^{0}$ 17.817/2004, que declarou como interesse nacional, dentre outras, a luta contra todas as formas de discriminação e a LIPT ${ }^{5,30}$.

Comparada à $\mathrm{ADI} \mathrm{n}^{0}$ 4.275/DF/STF/2018, a LIPT além de tratar-se de lei positivada, o texto do dispositivo prevê, entre outros, ações afirmativas e garantias específicas à População T, versando ainda sobre questões de visibilidade, autodeterminação de gênero, inclusão educacional, cotas para ingresso no funcionalismo público e, especificamente sobre mudança de nome, um procedimento mais célere e menos burocrático, que inclui a possibilidade de menores de idade realizarem a retificação documental mesmo sem a autorização dos pais, por exemplo4.

Com isso, verifica-se, em âmbito do Mercosul, uma compreensão mais salutar e menos heteronormativa acerca da compreensão do que se define por orientação sexual e identidade de gênero, expandindo-se o conceito de cidadania e de reconhecimento das diferenças para essas pessoas, cujos direitos passam a ser (re)afirmados ${ }^{12,13}$.

Mesmo que em ritmos e formas diferentes, ambos os países analisados apresentaram certa preocupação com a proteção e inserção social de transgêneros, ressalta-se, contudo, que a situação jurídica para transgêneros no Brasil é mais frágil se comparada à do país vizinho, tornando-se de extrema importância que as políticas públicas já estabelecidas sejam perpetuadas e que os direitos conquistados por jurisprudências indiquem uma lacuna legal a ser devidamente preenchida, considerando-se os objetivos de Direitos Humanos e o respeito aos Direitos Fundamentais.

\section{Referências}

1. Organização das Nações Unidas. Declaração Universal dos Direitos Humanos [Internet]. Paris: A Organização; 1948 [citado em 2019 fev. 14]. Disponível em: https://bit.ly/2vNPge1.

2. Organização dos Estados Americanos. Convenção Americana sobre Direitos Humanos [Internet]. San José: Conferência Especializada Interamericana sobre Direitos Humanos; 1969 [citado em 2019 fev. 14]. Disponível em: https://bit.ly/29HCHYS.

3. Organização dos Estados Americanos. Comissão Interamericana de Direitos Humanos. Convenção Interamericana para prevenir, punir e erradicar a violência contra a mulher. "Convenção de Belém do Pará" [Internet]. Belém: A Organização; 1994 [citado em 2019 fev. 14]. Disponível em: http://www.cidh. org/Basicos/Portugues/m.Belem.do.Para.htm.

4. Rodrigues J. LGBT [Internet]. Camba SV, organizadora. Brasília: Secretaria dos Direitos Humano da Presidência da República; 2015 [citado em 2019 fev. 14]. (Coleção Caravana de Educação em Direitos Humanos). Disponível em: http://flacso.org.br/files/2017/06/LGBT.pdf.

5. Supremo Tribunal Federal (BR). Ação Direta de Inconstitucionalidade no 4.275-1/600 [Internet]. Brasília: O Supremo; 2009 [citado em 2019 fev. 14]. Disponível em: https://bit.ly/2G2Kdwg. 
6. $\quad$ Parlamento del Uruguay (UY). Proyecto de Ley no 816 [Internet]. Montevideo: O Parlamento; 2017 [citado em 2019 fev. 14]. Disponível em: https://bit.ly/2NGTmkr.

7. Santos MFL, Arán M. A construção do dispositivo da transexualidade: saberes, tessituras e singularidades nas vivências trans [Internet]. Anais do $2^{\circ}$ Seminário Internacional Enlaçando Sexualidades; 2011 set. 4-6; Salvador. Salvador: EdUNEB; 2011 [citado em 2019 fev. 14]. Disponível em: https://bit.ly/2YSb9WI.

8. $\quad$ Temer T. As leis e projetos de lei sobre "ideologia de gênero" nas escolas: uma análise sob a perspectiva das competências legislativas em matéria educacional. In: Ranieri, NBS, Alves ALA, organizadoras. Direito à Educação e Direitos na Educação. São Paulo: Cátedra UNESCO de Direito à Educação/USP; 2018. p. 431-52.

9. Ferreira ABH. Novo dicionário Aurélio. Rio de Janeiro: Nova Fronteira; 1975.

10. Lopes ACV. Transexualidade: reflexos da redesignação sexual [Internet]. Anais do 70 Congresso Brasileiro de Direito de Família; 2009 out. 28-31; Belo Horizonte. Belo Horizonte: IBDFAM; 2009 [citado em 2019 fev. 14]. Disponível em: https://bit.ly/2Jz7wi7.

11. Corte Interamericana de Derechos Humanos (CR). Opinión Consultiva n 24, de 24 de noviembre de 2017: identidad de género, e igualdad y no discriminación a parejas del mismo sexo [Internet]. Costa Rica: A Corte; 2017 [citado en 2019 fev. 14]. Disponible: https://bit.ly/2Dc]p5p.

12. Arendt $\mathrm{H}$. The origins of totalitarianism [Internet]. New York: Meridian Books; 1991 [citado em 2019 fev. 14]. Disponível em: https://www.azioniparallele.it/images/materiali/Totalitarianism.pdf.

13. Santos BS. Reconhecer para libertar: os caminhos do cosmopolitanismo multicultural. Introdução: para ampliar o cânone do reconhecimento, da diferença e da igualdade. Rio de Janeiro: Civilização Brasileira; 2003.

14. Mastrantonio SAB. Ações afirmativas: promoção da cidadania empresarial. Curitiba: Jaruá; 2011.

15. Rios RR. O princípio da igualdade e a discriminação por orientação sexual: a homossexualidade no direito brasileiro e norte-americano. São Paulo: Revista dos Tribunais; 2002.

16. Presidência da República (BR). Casa Civil. Subchefia de Assuntos Jurídicos. Constituição da República Federativa do Brasil de 1988. DOU [Internet]; 1988 out. 5 [citado em 2019 fev. 14]. Disponível em: http://www.planalto.gov.br/ccivil 03/constituicao/constituicaocompilado.htm.

17. Moraes A. Direitos humanos fundamentais: teoria geral. 9 ed. São Paulo: Atlas; 2011.

18. Luhmann N. Das recht der gesellschaft. Frankfurt: Suhrkamp; 1993.

19. Miskolci R., Pelúcia L. Fora do sujeito e fora do lugar: reflexões sobre performatividade a partir de uma etnografia entre travestis. Gênero [Internet]. 2007 [citado em 2019 mai. 26];16(32):57-269. Disponível em: http://www.revistagenero.uff.br/index.php/revistagenero/article/view/155/98.

20. Silveira VO, Rocasolano MM. Direitos humanos: conceitos, significados e funções. São Paulo: Saraiva; 2010.

21. Trevisam E. Trabalho escravo no Brasil contemporâneo: entre as presas da clandestinidade e as garras da exclusão. Curitiba: Jaruá; 2015.

22. Moreira AJ. Cidadania sexual: estratégia para ações inclusivas. Belo Horizonte: Arraes Editores; 2017.

23. Fachin O. Fundamentos de metodologia. 6 ed. São Paulo: Saraiva; 2017.

24. Marrara T. Método comparativo e direito administrativo. Rev Jurid UNIGRAN [Internet]. 2014 [citado em 2019 fev. 14];16(32):25-37. Disponível em: https://bit.ly/32dWF5M.

25. Bento B. Nome social para pessoas trans: cidadania precária e gambiarra legal. Contemporânea [Internet]. 2014 [citado em 2019 fev. 14];4(1):165-82. Disponível em: http://www.contemporanea. ufscar.br/index.php/contemporanea/article/download/197/101.

26. Presidência da República (BR). Casa Civil. Subchefia de Assuntos Jurídicos. Decreto no 8.727, de 28 de abril de 2016. Dispõe sobre o uso do nome social e o reconhecimento da identidade de gênero de pessoas travestis e transexuais no âmbito da administração pública federal direta, autárquica e fundacional. DOU [Internet]. 2016 abr. 29 [citado em 2019 fev. 14]. Disponível em: http://www.planalto. gov.br/ccivil 03/ato2015-2018/2016/decreto/D8727.htm. 
27. Ministério da Saúde (BR). Secretaria de Atenção à Saúde. Portaria n 457, de 19 de agosto de 2008. Aprova, na forma dos anexos desta portaria a seguir descritos, a regulamentação do processo transexualizador no âmbito do Sistema Único de Saúde - SUS. DOU [Internet]. 2008 ago. 20 [citado em 2019 fev. 14]. Disponível em: https://bit.ly/2XBekWo.

28. Ministério da Saúde (BR). Portaria no 2.803, de 19 de novembro de 2013. Redefine e amplia o Processo Transexualizador no Sistema Único de Saúde (SUS). DOU [Internet]. 2013 nov. 21 [citado em 2019 fev. 14]. Disponível em: https://bit.ly/1Bipb2P.

29. Conselho Nacional de Justiça (BR). Corregedoria Nacional de Justiça. Provimento $n^{\circ} 73$, de 28 de junho de 2018. Dispõe sobre a averbação da alteração do prenome e do gênero nos assentos de nascimento e casamento de pessoa transgênero no Registro Civil das Pessoas Naturais (RCPN) [Internet]. Brasília; 2018 jun. 29 [citado em 2019 fev. 14]. Disponível em: http://www.cnj.jus.br/files/atos administrativos/ provimento-n73-28-06-2018-corregedoria.pdf.

30. Associação Nacional de Travestis e Transexuais. Mapa dos assassinatos de travestis e transexuais no Brasil em 2017 [Internet]. Brasília: A Associação; 2018 [citado em 2019 fev. 14]. Disponível em: https:// bit.ly/2CNO9fY.

31. Comissão Interamericana de Direitos Humanos. Organização dos Estados Americanos. Violência contra pessoas lésbicas, gays, bissexuais, trans e intersex nas Américas [Internet]. Washington, DC: A Organização; 2015 [citado em 2019 fev. 14]. Disponível em: http://www.oas.org/pt/cidh/docs/pdf/ ViolenciaPessoasLGBTI.pdf.

32. Presidência da República (BR). Casa Civil. Subchefia de Assuntos Jurídicos. Lei no 6.015, de 31 de dezembro de 1973. Dispõe sobre os registros públicos, e dá outras providências. DOU [Internet]. 1973 dez. 31 [citado em 2019 fev. 14]. Disponível em: https://bit.ly/2nBq32D. 